\title{
BLOCKADE OF THE RENIN-ANGIOTENSIN SYSTEM INHIBITS GROWTH OF COLORECTAL CANCER LIVER METASTASES IN THE REGENERATING LIVER
}

Running title: Blockade of the Renin-Angiotensin System Inhibits Growth of Colorectal Cancer Liver Metastases

Keywords: Colorectal cancer liver metastases; liver regeneration; partial hepatectomy; mouse model; tumor growth and stimulation

Manuscript type: Original research

\section{Koh SL, Ager EI, Costa PLN, Malcontenti-Wilson C, Muralidharan V, Christophi C}

The University of Melbourne, Department of Surgery, Austin Health, Burgundy Street, Heidelberg, VIC 3084, Australia

Corresponding author:

Dr Shir Lin $\mathrm{KOH}$

The University of Melbourne

Department of Surgery, Austin Health

Burgundy Street, Heidelberg, VIC 3084, AUSTRALIA

This work was supported by Austin Health Medical Research Foundation, The University of Melbourne, Australian Rotary Health, Priority-driven Collaborative Cancer Research Scheme and the Cancer Council of Victoria. Dr Ager was supported by an NHMRC post-doctoral training fellowship. There are no financial disclosures from any authors. 


\begin{abstract}
Partial hepatectomy $(\mathrm{PH})$, the preferred option for selected patients with colorectal cancer liver metastases (CRCLM), is associated with 40\%-80\% tumor recurrence rates. Renin-angiotensin system (RAS) blockade inhibits tumor growth and has been suggested to improve liver regeneration. We documented the effect of RAS blockade on tumor growth and liver regeneration in a murine model. CRCLM induction followed by $70 \% \mathrm{PH}$ was performed on 78 CBA mice. Liver regeneration (days 2,6) and CRCLM tumor load were measured by liver (and tumor) weights, percentage of CRCLM burden and tumor nodule count (days 16, 21). mRNA expression of the RAS components was characterised. Statistical analysis was performed using 2-independent sample T-test or Mann-Whitney test (SPSS). Captopril did not impair liver regeneration. By day 21, Captopril decreased tumor burden (percentage of CRCLM in the liver) $(48.7 \pm 4.7 \%$ control, $24.4 \pm 6.2$ Captopril; $\mathrm{p}=0.008)$, tumor volume $\left(1046.2 \pm 200.2 \mathrm{~mm}^{3}\right.$, $388.3 \pm 150.4 ; \mathrm{p}=0.02)$, tumor nodule count per image field $(181.1 \pm 28.5,68 \pm 17.6 ; \mathrm{p}=0.005)$ and tumor angiogenesis $\left(71.8 \pm 6.4\right.$ vessels $\left./ \mathrm{mm}^{2}, 43.1 \pm 7.6 ; \mathrm{p}=0.015\right)$ compared to controls. Captopril enhanced tumor apoptosis $(1 \pm 0.2 \%, 2.5 \pm 0.7 ; \mathrm{p}=0.028)$. Liver regeneration and tumor development increased liver ACE levels. Blockade of the RAS effectively retarded CRCLM tumor growth at the late stage of tumor development within the regenerating liver without impeding liver regeneration following $\mathrm{PH}$, via anti-angiogenesis and pro-tumor apoptosis. Captopril may be of therapeutic benefit in patients undergoing PH for CRCLM.
\end{abstract}

\title{
INTRODUCTION
}

Colorectal cancer (CRC) is the second leading cause of death across both genders worldwide. The majority of CRC-related deaths are associated with liver metastasis, which occurs in approximately $70 \%$ of patients $(1,2)$. Partial hepatectomy $(\mathrm{PH})$, often combined with systemic chemotherapy, is the preferred therapeutic option for eligible patients with colorectal cancer liver metastases (CRCLM) and can offer the potential for long-term survival. However, the success of $\mathrm{PH}$ is limited by several factors. Firstly, PH for CRCLM is associated with a significant rate of tumor recurrence, ranging from $40 \%$ to $80 \%$ (3) and approximately $50 \%$ of patients with CRCLM die from disease progression (4). Secondly, successful PH is dependent on adequate regenerative capacity of the liver to restore liver function. This may be impaired in situations of steatosis and steohepatitis commonly caused by conventional chemotherapy or other patient- 
dependent factors such as obesity and diabetes $(5,6)$. Other targeted treatments such as the epidermal growth factor (EGF) receptor inhibitor, gefitinib, and the anti-vascular endothelial growth factor (VEGF) monoclonal antibody, bevacizumab, are also not without side effects or tumor drug resistance (7). Therefore, novel strategies that can inhibit tumor recurrence without compromising the regeneration of the liver after resection would offer several advantages.

Local RAS (renin-angiotensin system) expression has been documented in various organs, along with its ability to regulate cellular proliferation, angiogenesis, and apoptosis, all of which are key processes in liver regeneration and tumor stimulation (8). Studies have shown inhibition of tumor growth by RAS blockade both in vitro (9-11) and in vivo (12-17). Recently, Kedika et al. showed that long-term use of ACE inhibitors may potentially reduce the incidence for CRC by inhibiting the development of advanced adenomatous colon polyps (18). In other studies, RAS blockade with ACE inhibition (ACEi) or angiotensin receptor blockers (ARBs) has been shown to promote liver regeneration in animal models (19-22). The main advantage of ACEi and ARBs over traditional cancer therapies is that they have been in clinical use as anti-hypertensives for the past 20 years with no severe side effects and may therefore offer a promising therapeutic strategy in the management of liver metastases following $\mathrm{PH}$.

The RAS can modify liver tumor growth and affect liver regeneration (8, 23). Several components of the RAS are expressed in primary CRC (24) and CRCLM (12). Pharmacological blockade of various components of the RAS inhibit CRCLM tumor growth, proliferation and angiogenesis $(12,13,17,19,25-28)$. RAS blockade has also been found to significantly enhance liver regeneration in animal models (19-22, 29). While the effects of the ACE inhibitor, captopril, on CRCLM and on the RAS expression in tumors have been documented (12), it is unknown whether these beneficial outcomes can be achieved in the same patient.

Based on our previously established separate mouse models of colorectal liver metastases (CRCLM) and liver regeneration, a combined mouse model of PH and CRCLM has been developed in this study as a research tool to investigate the effect of RAS blockade on CRCLM in the regenerating liver (30). 


\section{METHODS}

Experiments were performed with the approval of the Austin Health animal ethics committee. Eighty four inbred male CBA mice, 10-12 weeks old, weighing 26-32 g, acquired from Adelaide University animal facility, South Australia were utilised in this study. All mice were housed under standard conditions of controlled temperature and humidity and exposed to a 12 hourly light/dark cycle. They were provided with a standard laboratory diet and water ad libitum.

\section{Surgical Procedure for Partial Hepatectomy and Induction of Colorectal Cancer Liver} Metastases

Induction of CRCLM followed by $70 \% \mathrm{PH}$ was performed in 76 mice. Mice undergoing surgery were anaesthetized with a mixture of ketamine at $100 \mathrm{mg} / \mathrm{kg}$ (Parke Davis, Melbourne, VIC, Australia) and Xylazine at 10mg/kg (Bayer, Melbourne, VIC, Australia) via intraperitoneal injection. A long-acting analgesic, Carprofen (Pfizer, Melbourne, VIC, Australia) was administered at $10 \mathrm{mg} / \mathrm{kg}$ via subcutaneous injection at the time of anaesthesia. A longitudinal abdominal incision was used to expose all liver lobes and spleen. To mimic the more relevant clinical situation, CRCLM tumor induction was performed prior to $70 \% \mathrm{PH}$. CRCLM was induced with the murine colorectal cancer cell line (MoCR) (13). Briefly, $0.05 \mathrm{ml}$ of MoCR cell suspension containing $2.5 \times 10^{5}$ cells was injected in the mouse spleen after which the cells circulate for two minutes prior to splenectomy. Immediately following splenectomy, $70 \% \mathrm{PH}$ was performed by resection of the left posterior and median liver lobes of the mouse. $4 / 0$ silk sutures were applied across the pedicle, at the base of the lobe intended for surgical resection. The liver lobes were then excised distal to the applied suture ligation. Warm $0.9 \%$ saline was administered into the abdominal cavity to replenish fluid losses and prevent dehydration. The abdomen and skin were then closed in layers with running 4/0 silk sutures. Animals recovered on heat pads with access to food and water. All animals were monitored daily for signs of distress, including decreased mobility, hunched posture, ruffled fur, and loss of weight according to the animal monitoring sheet approved by the Austin Health Ethics Committee. At study endpoints, mice were anaesthetized with ketamine/xylazine mixture at days $2(\mathrm{~N}=6), 6(\mathrm{~N}=11), 16(\mathrm{~N}=$ $21)$ and $21(\mathrm{~N}=40)$ post-surgery. Six mice that did not undergo induction or surgery (normal mice) were used as baseline controls. Normal mice were anaesthetised and culled as aforementioned. 


\section{Blockade of the Renin-Angiotensin System using Captopril}

Captopril ( $\mathrm{pH}$ 7) was made fresh and administered at $250 \mathrm{mg} / \mathrm{kg}$ (at a volume of $0.3 \mathrm{ml}$ ) daily via intraperitoneal injections using a 30 gauge needle from the day of induction until the experimental endpoints. Control mice received an equivalent volume of the saline. Mice were monitored daily for any signs of distress or poor condition.

\section{Measurement of the Percentage of Liver Regenerated}

The regenerated liver mass was determined using an analytical balance, excluding the weight of remnant unresected liver lobes. The percentage of regenerated liver was measured by mouse liver-body-weight (LBW) ratio at day 2 and day 6. At days 16 and 21, liver regeneration was also assessed by liver volume.

\section{Measurement of CRCLM Tumor Burden}

At days 16 and 21, CRCLM tumor burden was determined by the percentage of liver volume taken up by tumors. Quantitative stereological assessment was performed to assess CRCLM tumor burden (Supplementary Fig 1). Every liver slice per mouse liver was processed using a standard paraffin processing protocol. Sections were cut into $1.5 \mathrm{~mm}$ sections in thickness using a multiple-blade fractionator. Digital images of whole liver containing tumors were captured using a Nikon Infinity 4 imaging software (Haiser RS 2 XA, SciTech, VIC, Australia). The areas of liver and tumor were digitally traced using an image analysis program (Image Pro Plus, version 5, MD, USA). Tumor burden was calculated as a total volume of tumors expressed as a percentage of total liver plus tumor volume. The mean percentage of tumor burden at the early (day 16) and late (day 21) stages of tumor growth were determined (mean \pm SEM).

\section{Quantitative Reverse-Transcription Polymerase Chain Reaction (qRT-PCR) for the Relative Quantification of Gene Expression of RAS Components}

RNA from liver and tumors was extracted (High Pure RNA Tissue Kit, Roche, Australia). cDNA synthesis was performed using the Superscript III First Strand Synthesis Kit (Invitrogen, Australia). Probes and primers for angiotensinogen, ACE, ACE2, AT1R, AT2R and the Mas receptor were designed using a software program, Primer Express, Version 1.0 (PE Applied Biosystems, USA). Primers and probes were purchased from Geneworks, Australia. All probes 
contained a fluorescence reporter (6-carboxytetramethylrhodamine [FAM]) at the 5' end and a fluorescent quencher (6-carboxytetramethylrhodamine [TAMRA]) at the 3' end. A commercially available predeveloped $18 \mathrm{~S}$ control kit labeled with the fluorescent reporter dye (FAM) on the 5' end and the quencher (TAMRA) on the 3' end (PE Applied Biosystems, Australia) were used as the housekeeping gene. Probe and primer sequences are listed in Table 1. For each plate, a negative reverse transcriptase (RT) control was added to the reaction in duplicates. qRT-PCR was performed using an ABI Prism 7700 Sequence Detector (PE Applied Biosystems). The qRTPCR reaction took place in $25 \mu 1$ volumes consisting of $12.5 \mu$ l Platinum ${ }^{\circledR}$ qPCR SuperMix-UDG

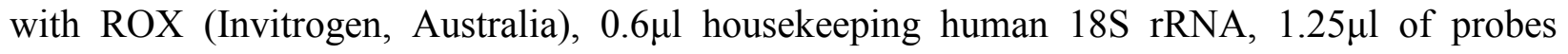
$(2 \mu \mathrm{M} / \mathrm{L})$ and both forward and reverse primers $(10 \mu \mathrm{M} / \mathrm{L})$. Each sample was run and analyzed in triplicates using between 5-100ng of cDNA in each reaction depending on the gene being assessed. Thermal cycling was initiated with a $50^{\circ} \mathrm{C}$ incubation for 2 minutes, followed by a denaturation step of 10 minutes at $95^{\circ} \mathrm{C}$ for 15 seconds, and $65^{\circ} \mathrm{C}$ for 1 minute. A multiplex comparative threshold cycle $\left(\mathrm{C}_{\mathrm{T}}\right)$ method was used. Analysis of relative gene expression from the qRT-PCR followed standard procedures $(31,32)$. The number of cycles to threshold was determined by interpolation from the fluorescence data, as described previously. The $\mathrm{C}_{\mathrm{T}}$ data generated from the real-time PCR reaction in triplicates was analysed for each well using a Microsoft Excel spreadsheet. Triplicates $\mathrm{C}_{\mathrm{T}}$ values for the target gene and endogenous control (18S rRNA) for each sample were averaged and the $\mathrm{C}_{\mathrm{T}}$ value for the endogenous control was subtracted from the target gene $\mathrm{C}_{\mathrm{T}}$ value. Target gene expression in the experimental group was normalized against the control group and the relative fold expression, $2-\Delta \mathrm{C}_{\mathrm{T}}$, was determined.

\section{Immunohistochemistry to Assess Cellular Apoptosis and Proliferation, and Tumor} Angiogenesis

Liver and tumors were fixed in 10\% neutral-buffered formalin (Sigma Aldrich, Castle Hill, NSW, Australia) at room temperature for 24 hours before being stored in $70 \%$ ethanol until further processing. Paraffin-embedded tissue sections ( $4 \mu \mathrm{m})$ (Leica RM2245, Wetzlar, Germany) were used for immunohistochemistry staining. Primary antibodies used included rabbit antiactive Caspase-3 subunit 17 antibody $(0.67 \mu \mathrm{g} / \mathrm{ml}$, AF835, R\&D Systems), rat anti-mouse antiCD34 antibody $(2 \mu \mathrm{g} / \mathrm{ml}$, MCA18256, Serotec) and mouse anti-Ki67 antibody $(4 \mu \mathrm{g} / \mathrm{ml}, 4203-1$ SP6, DKSH Australia Pty Ltd). For anti-Caspase-3 and anti-CD34 antibodies, antigen retrieval 


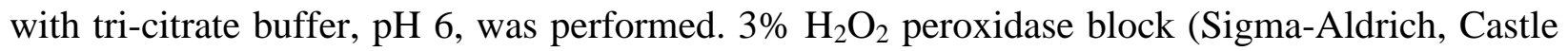
Hill, NSW, Australia) was used to block endogenous peroxidases. 10\% normal goat serum (016201, Invitrogen, CA, USA) was applied to block sections (30 minutes) prior to primary antibody incubation. Slides were incubated with anti-active Caspase-3 antibody for 2 hours at $37^{\circ} \mathrm{C}$, whereas anti-CD34 antibody was incubated at $37^{\circ} \mathrm{C}$ for $1 \mathrm{~h}$ followed by at $4{ }^{\circ} \mathrm{C}$ overnight. Anti-CD34 sections were also incubated with a linking polyclonal rabbit anti-rat biotinylated antibody (Dako Envision Plus) at $37^{\circ} \mathrm{C}$ for 30 minutes prior to the secondary antibody step. Slides were incubated with goat anti-rabbit secondary antibody (Envision+® System-HRP kit) (60 minutes) and positive staining visualised with DAB substrate chromogen solution (Envision+® System-HRP kit) (4 minutes). Sections were counterstained with Mayer's Haematoxylin (Sigma-Aldrich, Castle Hill, NSW, Australia). Sections stained with anti-Ki67 antibody were performed in a similar way with some modifications: endogenous peroxidase block with $3 \% \mathrm{H}_{2} \mathrm{O}_{2}$ was performed prior to the antigen retrieval step (target retrieval solution pH 9, S2367, Dako Australia Limited), sections were blocked using the Ultra V block (Thermo Scientific Australia) and incubated with anti-Ki67 antibody for 2 hours at $37^{\circ} \mathrm{C}$.

\section{Liver and Tumor Cell Apoptosis and Proliferation, and Tumor Angiogenesis Quantitation}

Random images were taken of stained sections with a digital microscope (Nikon Coolscope II,

Nikon, Japan) using X10 (angiogenesis), X20 (proliferation) and X40 (apoptosis) magnifications. 10-60 random images per sample were examined (except when the tumor size limited the number of images). Staining was assessed using ImagePro Plus software (Version 5, MD, USA). The number of positively-stained (apoptotic or proliferative) cells were quantified and expressed as a percentage of total hepatocytes/tumor cells per image field respectively. Tumor angiogenesis was assessed as tumor vessel density, which provides an indication of angiogenic potential, determined by quantitating the number of CD34 positive vessels per viable tumour area.

\section{Statistical Analysis}

At study endpoints, experimental data (mean \pm SEM) were assessed for normality and compared by 2 -independent sample T-test or non-parametric, Mann-Whitney test, as appropriate, using the 
Statistical Package for the Social Sciences (SPSS, Chicago, version 18). A p-value of equal and/or lesser than 0.05 was deemed as statistically significant.

\section{RESULTS}

Higher CRCLM Tumor Burden at the Later Stage of Tumor Development in the Regenerating Tumor-Bearing Liver

In this study, we have utilised our previously established combined mouse model of CRCLM tumor development and liver regeneration (30). At days 16 and 21, CRCLM were evident in the regenerating livers (Fig 1). Tumor burden (percentage of CRCLM tumor burden of the liver), total liver plus tumor volumes, tumor nodule count per image field and tumor volume alone (without liver volume) of the regenerating tumor-bearing liver were higher at day 21 than day 16 (Fig 1, Fig 2; Table 2). CRCLM tumor burden was significantly greater at day 21 when CRCLM is fully established compared to day 16 ( $\mathrm{p}<0.001$; Fig 1 ; Table 2). Tumor volumes were significantly higher at the late stage of tumor development compared to the earlier phase $(\mathrm{p}=$ 0.022; Fig 2; Table 2). Total liver plus tumor volume was significantly higher at the late stage of tumor growth compared to its early stage ( $p=0.003$; Fig 1 ; Table 2$)$.

\section{Captopril Inhibits Colorectal Cancer Liver Metastases (CRCLM) at the Late Stage of Tumor Development}

Captopril inhibited CRCLM at the late stage of tumor development. At day 21, Captopril treatment significantly decreased CRCLM tumor burden $(\mathrm{p}=0.008)$, the percentage of liver and tumor weights to body weight ratio (128.3 $\pm 9 \%$ Captopril, $202.4 \pm 16$ control; $\mathrm{p}<0.01$ ) (Fig 1), the number of tumor nodules per image field in the regenerating CRCLM mouse livers $(\mathrm{p}=$ 0.005; Fig 2; Table 2), total liver and tumor volume ( $\mathrm{p}=0.048$; Fig 1; Table 2) and total tumor volume ( $\mathrm{p}=0.02$; Fig 2; Table 2) compared to controls. In contrast, Captopril did not significantly affect the early stages of tumor development (Fig 1, Fig 2).

\section{Effects of Captopril on Tumor Cell Apoptosis and Proliferation in the Regenerating Liver}

As Captopril significantly inhibited CRCLM at the late stage of tumor development, the percentage of tumor cell apoptosis was assessed in this study. Apoptotic cells, as assessed using an antibody against active caspase-3, were stained dark brown predominantly in the cytoplasm 
and peri-nucleus of cells (Fig 3a, Fig 3b). At day 21, the percentage of tumor cells undergoing apoptosis was significantly increased by Captopril treatment (Captopril $2.5 \pm 0.7 \%$ compared to controls $1 \pm 0.2 ; \mathrm{p}=0.028$; Fig $3 \mathrm{e}$ ). Tumor cell proliferation was measured using the anti-Ki67 antibody and proliferating cells were stained dark brown in the nucleus (Fig 3c, Fig 3d). At day 21 tumor cell proliferation was not altered by captopril treatment (Captopril $69 \pm 6.3 \%$, control $73.2 \pm 3.6 ; p=0.575 ;$ Fig $3 f)$. As expected from our findings, Captopril did not alter tumor cell proliferation compared to controls at day $16(68.2 \pm 5.9,65.9 \pm 2.8 ; p=0.696$; Fig 3f $)$. There was no difference in tumor cells undergoing proliferation between the early and late phases of tumor development (day 16 and day 21) in either control or treated groups (control, p = 0.747; Captopril, $\mathrm{p}=0.327$; Fig 3f).

\section{Captopril Decreased Tumor Angiogenesis at the Late Stage of Tumor Growth}

Tumor vessels stained positive with anti-CD34 antibody at days 16 and 21 in both the control and Captopril-treated tumors (Fig 4a). Captopril did not significantly alter tumor angiogenesis at day 16 ( $\mathrm{p}=0.401$; Fig 4b). However, at day 21, Captopril-treated tumors showed significantly decreased tumor angiogenesis compared to controls (Captopril $43.1 \pm 7.6$ number of tumor vessels $/ \mathrm{mm}^{2}$ tumor area, Control $71.8 \pm 6.4 ; \mathrm{p}=0.015$; Fig. $4 \mathrm{~b}$ ).

\section{Captopril did not Impede Liver Regeneration in the Tumor-Bearing Liver}

The percentage of regenerated liver at day 2 (52.9 $\pm 1.3 \%$, Captopril, $50.9 \pm 2$ control; $p=0.449)$ and day $6(71.8 \pm 0.9 \%$ Captopril, $73.6 \pm 1.9$ control; $\mathrm{p}=0.453)$ were similar between the control and treated groups (Fig 5a). As expected, Captopril did not affect tumor-bearing liver volume compared to control at day 16 (684.8 \pm 81.4 Captopril, $709.2 \pm 36.2$ control; $\mathrm{p}=0.778)$ or day 21 (886.1 $\pm 65.17 \mathrm{~mm}^{3}$ Captopril, $1044.1 \pm 115.8$ control; $\mathrm{p}=0.254$; Fig 5b). Apoptotic hepatocytes showed cytoplasmic staining (Fig 5e), whereas nuclei staining of proliferating hepatocytes were observed (Fig 5g). Both hepatocyte apoptosis and proliferation were unaltered by Captopril compared to control livers at day 21 (Fig 5c, Fig 5d). Hepatocyte proliferation at day 16 was also unaltered following Captopril treatment compared to controls $(\mathrm{p}=0.281, \mathrm{p}=$ 0.53 respectively; Fig 5d). 


\section{Changes in the Angiotensin-Converting Enzyme (ACE) mRNA Expression Levels}

\section{Following Liver Regeneration and CRCLM Tumor Development}

At day 16, liver and tumor ACE levels were unchanged by Captopril treatment, although Captopril-treated liver showed increased ACE expression compared to unresected non-tumor bearing (normal) liver (Fig 6a). Similarly, at day 21, Captopril appeared to have no effect on ACE expression in either the tumor or liver (Fig 6b) compared to the respective controls. ACE expression was increased in the control liver compared to normal liver (Fig 6b). There was a marked increase in ACE expression from both control and Captopril-treated tumors at day 21 compared to the surrounding liver that was not evident at day 16 (Fig 6b).

\section{DISCUSSION}

Partial hepatectomy $(\mathrm{PH})$, often combined with systemic chemotherapy, is the preferred therapeutic option for eligible patients with colorectal cancer liver metastases (CRCLM) and can offer the potential for long-term survival. However, the benefit of PH can be compromised by the side effects of conventional chemotherapy or other patient-dependent factors such as obesity and diabetes $(5,6)$. We have previously shown that Captopril inhibits tumor development of CRCLM via anti-angiogenic actions while leaving the liver sinusoids unimpaired (13), and that Captopril enhances liver regeneration in separate animal models (33). This study is the first to investigate the effects of blockade of the RAS in a clinically relevant mouse model of CRCLM in the regenerating liver. Here we showed that Captopril treatment can inhibit CRCLM following $\mathrm{PH}$ in the regenerating liver while still allowing liver regeneration to occur unimpeded.

Our data suggests that Captopril exerts its greatest effect on established tumors as only late stage (day 21) tumor growth was inhibited by treatment. The tumor-inhibitory effects of Captopril were associated with an anti-angiogenic effect with a significant reduction in tumor vessel density, and increased tumor cell apoptosis. In parallel to our findings, studies have observed decreased tumor vessel density, high proliferative index while tumor apoptosis was increased following endostatin, an anti-angiogenic, therapy $(13,34)$. We and others have shown that the growth and angiogenesis of established CRCLM (13), Lewis lung carcinoma, T241 fibrosarcoma, EOMA hemangioendothelioma and melanoma $(34,35)$ and human epidermoid tumor xenograft (36) were potently suppressed by RAS inhibition or anti-angiogenic therapy. 
Studies suggest that Captopril has the unique ability to inhibit angiogenesis by encouraging the formation of angiostatin, a potent angiogenic inhibitor $(35,37,38)$. RAS regulates VEGFmediated angiogenesis in hepatocarcinogenesis, and that treatment with ACE inhibition significantly inhibits hepatocarcinogenesis along with suppression of neovascularization and VEGF expression in the liver (39).

Our current findings support other studies that have reported higher ACE mRNA expression levels in liver metastases compared to the tumor-bearing liver (12). However, while Neo et al found that ACE expression could be altered by captopril treatment (12), we did not observe any significant changes in ACE with treatment. These contrasting results indicate that regeneration may regulate differences in the transcriptional control of ACE. We also found that the classical RAS pathway generally had higher expression in the liver compared to tumors, while the alternative RAS components, MasR and AT2R, were upregulated in the tumors but not in the liver (Supplementary). These results suggest that stimulation of the alternative RAS may further inhibit tumor growth when administered in conjunction with Captopril treatment.

Results from a previous study by our group showed no survival benefit in mice with CRCLM following Captopril treatment for 21 days (13). These results suggest that, in the absence of other treatment modalities (i.e. chemotherapeutics), Captopril may need to be administered for an extended period of time to observe a survival benefit. Moreover, while Captopril inhibits tumor growth, tumors do not regress but continue to grow, albeit at a reduced rate. Therefore, it is unlikely that Captopril monotherapy would be successful in the clinic. Nevertheless, our results suggest that Captopril could be used to reduce the dose of more toxic chemotherapeutic agents following $\mathrm{PH}$.

Although other therapies such as anti-EGF or anti-VEGF improved patient outcomes when administered alone, in combination with chemotherapy and $\mathrm{PH}$, neither of these treatments improved patient outcomes (40). The lack of improvement in the combination therapy may be explained by impaired liver regeneration following $\mathrm{PH}$, or other side effects such as steatosis and steohepatitis commonly caused by conventional chemotherapy, which can contribute to the poor patient outcomes. We have demonstrated that Captopril inhibited CRCLM in the regenerating 
liver, while liver regeneration was unhindered. This is of particular importance as other anticancer treatments currently offered to CRCLM patients in conjunction to major PH are associated with steatosis, liver damage, compromised liver recovery and liver regeneration, which ultimately reduces the efficacy of PH as well as contributing to patient mortality (40). In contrast, Captopril treatment did not impair liver recovery and thus could reduce CRCLM morbidity and mortality associated with insufficient liver regeneration. Once liver function has resumed, patients could then be placed on standard chemotherapies with or without ongoing Captopril treatment.

\section{Conclusions}

Our current findings suggest that Captopril treatment regresses CRCLM in the regenerating liver without impairing liver recovery following major $\mathrm{PH}$. We have illustrated the potential of Captopril to enhance the beneficial effects of surgery for patients with CRCLM.

\section{Acknowledgements}

This work has been supported by Austin Health Medical Research Foundation, The University of Melbourne, Australian Rotary Health, Priority-driven Collaborative Cancer Research Scheme and the Cancer Council of Victoria. Dr Ager was supported by an NHMRC post-doctoral training fellowship.

1. Saenz NC, Cady B, McDermott WV, Jr., Steele GD, Jr. Experience with colorectal carcinoma metastatic to the liver. Surg Clin North Am. 1989 Apr;69(2):361-70.

2. Pestana C, Reitemeier RJ, Moertel CG, Judd ES, Dockerty MB. The Natural History of Carcinoma of the Colon and Rectum. Am J Surg. 1964 Dec;108:826-9.

3. Fong Y, Cohen AM, Fortner JG, Enker WE, Turnbull AD, Coit DG, et al. Liver resection for colorectal metastases. J Clin Oncol. 1997 Mar;15(3):938-46.

4. IARC. International Agency for Research on Cancer Report. Geneva: World Health Organisation; 20082008 Contract No.: Document Number|.

5. Fong Y, Bentrem DJ. CASH (Chemotherapy-Associated Steatohepatitis) costs. Ann Surg. 2006 Jan;243(1):8-9. 
6. Vauthey JN, Pawlik TM, Ribero D, Wu TT, Zorzi D, Hoff PM, et al. Chemotherapy regimen predicts steatohepatitis and an increase in 90-day mortality after surgery for hepatic colorectal metastases. J Clin Oncol. 2006 May 1;24(13):2065-72.

7. Widakowich C dCG, Jr., de Azambuja E, Dinh P, Awada A. . Review: side effects of approved molecular targeted therapies in solid cancers. . Oncologist 2007;12(12):1443-55.

8. Koh SL, Ager EI, Christophi C. Liver regeneration and tumour stimulation: implications of the renin-angiotensin system. Liver Int. 2010 Jul 12;30(10):1414-26.

9. Uemura H, Ishiguro H, Nakaigawa N, Nagashima $\mathrm{Y}$, Miyoshi $\mathrm{Y}$, Fujinami K, et al. Angiotensin II receptor blocker shows antiproliferative activity in prostate cancer cells: a possibility of tyrosine kinase inhibitor of growth factor. Mol Cancer Ther. 2003 Nov;2(11):113947.

10. Attoub S GA, Al-Salam S, Al Sultan MA, John A, Nicholls MG, et al. . Captopril as a potential inhibitor of lung tumor growth and metastasis. . Ann N Y Acad Sci 2008;1138:65-72.

11. Greco AJ MR, Fokin A, Jr., Baber SR, Kadowitz PJ. . Angiotensin-(1-7) potentiates responses to bradykinin but does not change responses to angiotensin I. . Can J Physiol Pharmacol 2006;84(11):1163-75.

12. Neo JH, Ager EI, Angus PW, Zhu J, Herath CB, Christophi C. Changes in the renin angiotensin system during the development of colorectal cancer liver metastases. BMC Cancer. 2010 Apr 10;10(1):134.

13. Neo JH, Malcontenti-Wilson C, Muralidharan V, Christophi C. Effect of ACE inhibitors and angiotensin II receptor antagonists in a mouse model of colorectal cancer liver metastases. J Gastroenterol Hepatol. 2007 Apr;22(4):577-84.

14. Miyajima A, Kosaka T, Asano T, Seta K, Kawai T, Hayakawa M. Angiotensin II type I antagonist prevents pulmonary metastasis of murine renal cancer by inhibiting tumor angiogenesis. Cancer Res. 2002 Aug 1;62(15):4176-9.

15. Fujita M, Hayashi I, Yamashina S, Itoman M, Majima M. Blockade of angiotensin AT1a receptor signaling reduces tumor growth, angiogenesis, and metastasis. Biochem Biophys Res Commun. 2002 Jun 7;294(2):441-7.

16. Noguchi R, Yoshiji H, Kuriyama S, Yoshii J, Ikenaka Y, Yanase K, et al. Combination of interferon-beta and the angiotensin-converting enzyme inhibitor, perindopril, attenuates murine 
hepatocellular carcinoma development and angiogenesis. Clin Cancer Res. 2003 Dec 1;9(16 Pt 1):6038-45.

17. Volpert OV, Ward WF, Lingen MW, Chesler L, Solt DB, Johnson MD, et al. Captopril inhibits angiogenesis and slows the growth of experimental tumors in rats. J Clin Invest. 1996 Aug 1;98(3):671-9.

18. Kedika R PM, Pena Sahdala HN, Mahgoub A, Cipher D, Siddiqui AA. . Long-term use of angiotensin converting enzyme inhibitors is associated with decreased incidence of advanced adenomatous colon polyps. . J Clin Gastroenterol 2011;45(2):e12-6.

19. Yayama K, Miyagi R, Sugiyama K, Sugaya T, Fukamizu A, Okamoto H. Angiotensin II regulates liver regeneration via type 1 receptor following partial hepatectomy in mice. Biol Pharm Bull. 2008 Jul;31(7):1356-61.

20. Yayama K, Sugiyama K, Miyagi R, Okamoto H. Angiotensin-converting enzyme inhibitor enhances liver regeneration following partial hepatectomy: involvement of bradykinin B2 and angiotensin AT1 receptors. Biol Pharm Bull. 2007 Mar;30(3):591-4.

21. Ramalho FS, Ramalho LN, Castro ESJO, Zucoloto S, Correa FM. Angiotensinconverting enzyme inhibition by lisinopril enhances liver regeneration in rats. Braz J Med Biol Res. 2001 Jan;34(1):125-7.

22. Ramalho FS, Ramalho LN, Castro-e-Silva Junior O, Zucoloto S, Correa FM. Effect of angiotensin-converting enzyme inhibitors on liver regeneration in rats. Hepatogastroenterology. 2002 Sep-Oct;49(47):1347-51.

23. Ager EI, Neo J, Christophi C. The renin-angiotensin system and malignancy. Carcinogenesis. 2008 Sep;29(9):1675-84.

24. Ohta T, Amaya K, Yi S, Kitagawa H, Kayahara M, Ninomiya I, et al. Angiotensin converting enzyme-independent, local angiotensin II-generation in human pancreatic ductal cancer tissues. Int J Oncol. 2003 Sep;23(3):593-8.

25. Sato T, El-Assal ON, Ono T, Yamanoi A, Dhar DK, Nagasue N. Sinusoidal endothelial cell proliferation and expression of angiopoietin/Tie family in regenerating rat liver. Journal of hepatology. 2001 May;34(5):690-8.

26. Ager EI, Chong WW, Wen SW, Christophi C. Targeting the angiotensin II type 2 receptor (AT2R) in colorectal liver metastases. Cancer Cell Int. 2010;10:19. 
27. Balabaud C, Bioulac-Sage P, Desmouliere A. The role of hepatic stellate cells in liver regeneration. Journal of hepatology. 2004 Jun;40(6):1023-6.

28. Ramalho FS, Alfany-Fernandez I, Casillas-Ramirez A, Massip-Salcedo M, Serafin A, Rimola A, et al. Are Angiotensin II receptor antagonists useful strategies in steatotic and nonsteatotic livers in conditions of partial hepatectomy under ischemia-reperfusion? J Pharmacol Exp Ther. 2008 Dec 30;329(1):130-40.

29. Ramalho LN, Zucoloto S, Ramalho FS, Castro-e-Silva O, Jr., Correa FM. Effect of antihypertensive agents on stellate cells during liver regeneration in rats. Arq Gastroenterol. 2003 Jan-Mar;40(1):40-4.

30. Harun N. CPaCC. Tumour growth stimulation following partial hepatectomy in mice is associated with increased upregulation of c-Met. Clin Exp Metastasis. 2013;E-pub ahead of print.

31. Stahlberg A KM, Pfaffl M. . Comparison of reverse transcriptases in gene expression analysis. . Clin Chem 2004;50(9):1678-80.

32. Pfaffl M. A new mathematical model for relative quantification in real-time RT-PCR. . Nucleic Acids Res. 2001;29(9):e45.

33. Koh SL, Ager E, Malcontenti-Wilson C, Muralidharan V, Christophi C. Blockade of the renin-angiotensin system improves the early stages of liver regeneration and liver function. $\mathbf{J}$ Surg Res. [Research Support, Non-U.S. Gov't]. 2013 Jan;179(1):66-71.

34. O'Reilly MS, Boehm T, Shing Y, Fukai N, Vasios G, Lane WS, et al. Endostatin: an endogenous inhibitor of angiogenesis and tumor growth. Cell. 1997 Jan 24;88(2):277-85.

35. de Groot-Besseling RR, Ruers TJ, van Kraats AA, Poelen GJ, Ruiter DJ, de Waal RM, et al. Anti-tumor activity of a combination of plasminogen activator and captopril in a human melanoma xenograft model. International journal of cancer Journal international du cancer. [Research Support, Non-U.S. Gov't]. 2004 Nov 1;112(2):329-34.

36. Oliner J, Min H, Leal J, Yu D, Rao S, You E, et al. Suppression of angiogenesis and tumor growth by selective inhibition of angiopoietin-2. Cancer Cell. 2004 Nov;6(5):507-16.

37. Heffelfinger SC. The renin angiotensin system in the regulation of angiogenesis. Curr Pharm Des. 2007;13(12):1215-29.

38. Gately S, Twardowski P, Stack MS, Cundiff DL, Grella D, Castellino FJ, et al. The mechanism of cancer-mediated conversion of plasminogen to the angiogenesis inhibitor 
angiostatin. Proceedings of the National Academy of Sciences of the United States of America. [Research Support, Non-U.S. Gov't

Research Support, U.S. Gov't, Non-P.H.S.

Research Support, U.S. Gov't, P.H.S.]. 1997 Sep 30;94(20):10868-72.

39. Yoshiji H, Noguchi R, Kuriyama S, Yoshii J, Ikenaka Y, Yanase K, et al. Suppression of renin-angiotensin system attenuates hepatocarcinogenesis via angiogenesis inhibition in rats. Anticancer research. 2005 Sep-Oct;25(5):3335-40.

40. Barugel ME, Vargas C, Krygier Waltier G. Metastatic colorectal cancer: recent advances in its clinical management. Expert Rev Anticancer Ther. 2009 Dec;9(12):1829-47.

Table 1 Forward and reverse primers, and probe sequences used for quantitative reversetranscription polymerase chain reaction listed from the 5' to 3' direction.

\begin{tabular}{|c|c|c|c|c|c|}
\hline Gene & Primer & Primer Sequence & Size (bp) & Probe & Size (bp) \\
\hline \multirow{5}{*}{$\begin{array}{l}\text { Angiotensin- } \\
\text { converting } \\
\text { enzyme }\end{array}$} & \multirow[t]{3}{*}{ Forward } & CAGAATCTACT & 24 & CAACAAGACTG & \multirow[t]{5}{*}{25} \\
\hline & & CCACTGGCAAG & & CCACCTGCTGG & \\
\hline & & GT & & TCC & \\
\hline & \multirow[t]{2}{*}{ Reverse } & CTGCTCCAGGC & 21 & & \\
\hline & & TTTCGTCTAA & & & \\
\hline \multirow{4}{*}{$\begin{array}{c}\text { Angiotensin } \\
\text { Type } 1 \\
\text { Receptor }\end{array}$} & \multirow[t]{2}{*}{ Forward } & GGGCAGTTTAT & 22 & \multirow{4}{*}{$\begin{array}{l}\text { TACCAGTGGCC } \\
\text { CTTCGGCAATC } \\
\text { A }\end{array}$} & \multirow[t]{4}{*}{23} \\
\hline & & ACCGCTATGGA & & & \\
\hline & \multirow[t]{2}{*}{ Reverse } & TGGCCGAAGCG & 20 & & \\
\hline & & ATCTTACAT & & & \\
\hline \multirow{5}{*}{$\begin{array}{c}\text { Angiotensin } \\
\text { Type } 2 \\
\text { Receptor }\end{array}$} & \multirow[t]{3}{*}{ Forward } & ATTACCTGCAT & 24 & ACCAATCGGTC & \multirow[t]{5}{*}{30} \\
\hline & & GAGTGTCGATA & & ATCTACCCTTT & \\
\hline & & GG & & TCTGTCTC & \\
\hline & \multirow[t]{2}{*}{ Reverse } & AGATGCTTGCC & 20 & & \\
\hline & & AGGGATTCC & & & \\
\hline Mas Receptor & Forward & TGTGGGCACTT & 19 & CACCATGGAGT & 20 \\
\hline
\end{tabular}




\begin{tabular}{|lll|}
\hline \multicolumn{1}{|l|}{ TCGTGCTT } & ATGTCATGT \\
\cline { 2 - 3 } Reverse & AATGACTCTCT 23 \\
& TCTCCGCTGTC \\
& A \\
\hline
\end{tabular}


Table 2 Comparison of percentage of liver metastases, tumor and liver volumes and tumor nodule count of mouse livers with colorectal cancer liver metastases at day 16 and day 21 after $70 \%$ partial hepatectomy and the statistical significance (p-value) between groups.

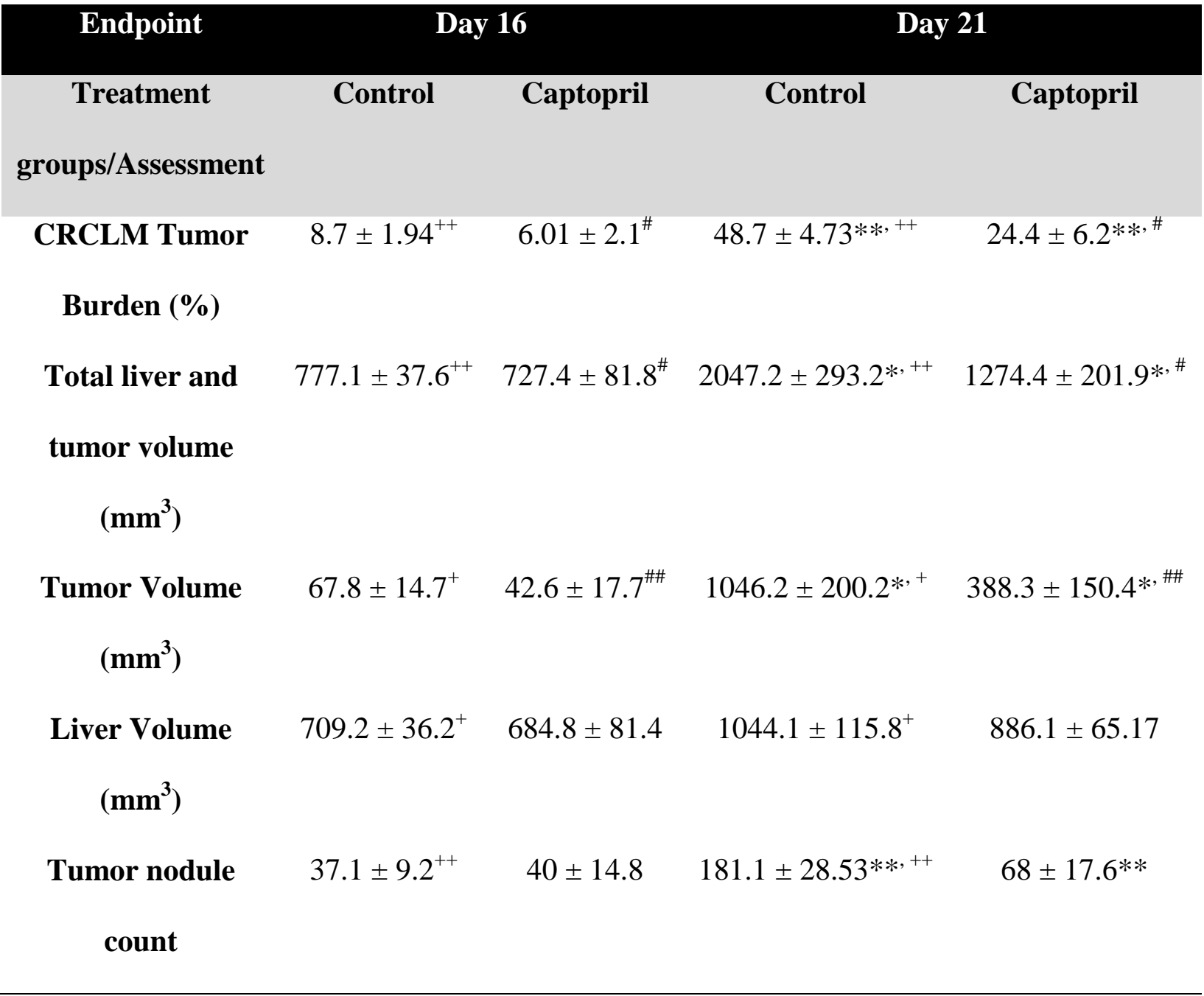

Fig 1 Macroscopic images representing mouse liver with colorectal cancer liver metastases (CRCLM) following 70\% partial hepatectomy of the (a) control group at day 16, (b) control at day 21, (c) Captopril-treated at day 16 and (d) Captopril-treated at day 21. Scale bar represents $1 \mathrm{~cm}$. e Captopril treatment decreased percentage of liver metastases $(24.4 \pm 6.22 \%)$ compared to controls $(48.7 \pm 4.73)$ at day 21 . Captopril $(6.01 \pm 2.1 \%)$ did not significantly alter the percentage of CRCLM compared to control livers $(8.7 \pm 1.94)$ at day $16(p=0.368)$. $\mathbf{f}$ Effects of Captopril on liver regeneration (total liver and tumor load to mouse body weight ratio) in mice with colorectal cancer liver metastases (CRCLM) 16 and 21 days after 70\% partial hepatectomy (PH). Captopril $(128.3 \pm 8.99 \%)$ decreased the percentage of liver regeneration of mouse livers with CRCLM following $70 \%$ PH compared to controls $(202.4 \pm 15.95)$ at day 21 ( $\mathrm{p}<0.01)$. 
Captopril $(92 \pm 2.4 \%)$ did not significantly alter the percentage of liver regeneration of mouse livers with CRCLM following 70\% PH compared to controls $(98.1 \pm 3.9)$ at day $16(\mathrm{p}=0.202)$. g Effects of Captopril on total liver and tumor volume in mice with colorectal cancer liver metastases (CRCLM) 16 and 21 days after 70\% partial hepatectomy (PH). Captopril decreased total tumor plus liver volume $(1274.4 \pm 201.9)$ compared to control $\left(2047.2 \pm 293.2 \mathrm{~mm}^{3}\right)$ at day 21. Captopril $\left(727.4 \pm 81.8 \mathrm{~mm}^{3}\right)$ did not significantly alter the total liver and tumor volume compared to controls $(777.1 \pm 37.6 ; \mathrm{p}=0.598)$ at day 16 .

Fig 2 Effects of Captopril on (a) number of tumor nodules per image field and (b) tumor volume of colorectal cancer liver metastases (CRCLM) in the regenerating liver at days 16 and 21. Captopril decreased $(68 \pm 17.6)$ tumor nodule count compared to controls $(181.1 \pm 28.53)$ at day 21. There was no significant difference between the captopril-treated (40 \pm 14.8$)$ and control livers $(37.1 \pm 9.2)$ at day $16(\mathrm{p}=0.869)$. Captopril $\left(42.6 \pm 17.7 \mathrm{~mm}^{3}\right)$ did not significantly alter tumor volume compared to controls $(67.8 \pm 14.7)$ at day $16(\mathrm{p}=0.153)$.

Fig 3 Effects of Captopril on tumor cell apoptosis and proliferation of colorectal cancer liver metastases following $70 \%$ partial hepatectomy $(\mathrm{PH})$ at days 16 and/or day 21 . a, b Immunohistochemical staining of tumor cell apoptosis stained by anti-active Caspase-3 antibody in (a) control and (b) Captopril-treated tumors. Apoptotic tumor cells were stained dark brown. c, d Immunohistochemical staining of proliferating tumor cell using anti-Ki67 antibody in (c) control and (d) Captopril-treated tumors on day 16. Proliferating tumor cells were stained dark brown. e Captopril increased percentage of tumor cell apoptosis compared to controls at day 21 (captopril $2.5 \pm 0.7 \%$ compared to controls $1 \pm 0.2 ; \mathrm{p}=0.028)$. f At day 21, Captopril (69.04 \pm $6.34 \%$ ) did not affect the percentage of tumor cell proliferation compared to controls (73.21 \pm $3.58 ; \mathrm{p}=0.575)$. Similarly, at day 16 , Captopril $(68.2 \pm 5.86 \%)$ did not significantly alter the percentage of tumor cell proliferation compared to controls $(65.9 \pm 2.83 ; \mathrm{p}=0.696)$. There was also no difference in tumor cell proliferation between the control groups at day 16 and day 21 (p $=0.747$ ). Similarly, tumor cell proliferation was similar between the Captopril-treated liver groups at day 16 and day $21(\mathrm{p}=0.327)$.

Fig 4 Effects of Captopril on tumor angiogenesis of colorectal cancer liver metastases measured by the number of tumor vessels per tumor area at days 16 and 21 following $70 \%$ partial hepatectomy (PH). a Immunohistochemical staining of tumor blood vessels in the control and Captopril-treated groups at days 16 and 21 (dark brown). b Captopril did not significantly alter tumor angiogenesis at day 16 (Captopril $43 \pm 6.2$, Control $59.7 \pm 11.3, \mathrm{p}=0.401$ ). At day 21 , Captopril significantly decreased tumor angiogenesis compared to controls (Captopril $43.1 \pm 7.6$ number of tumor vessels $/ \mathrm{mm}^{2}$ tumor area, $71.8 \pm 6.4 ; \mathrm{p}=0.015$ ).

Fig 5a Effects of Captopril on liver regeneration measured by the percentage of regenerated liver in mice with colorectal cancer liver metastases (CRCLM) 2 days and 6 days after $70 \%$ partial hepatectomy $(\mathrm{PH})$. Captopril did not significantly alter the percentage of regenerated liver compared to control at day $2(\mathrm{p}=0.449)$. Percentage of regenerated liver in the Captopril and 
control tumor-bearing livers were also similar at day $6(\mathrm{p}=0.453)$. b Effects of Captopril on tumor-bearing liver volume in mice with colorectal cancer liver metastases (CRCLM) 21 days after $70 \%$ partial hepatectomy $(\mathrm{PH})$. Liver volume was unchanged by Captopril $(\mathrm{p}=0.254)$ at day 21. Liver volume was also unaltered by Captopril at day $16\left(684.8 \pm 81.4 \mathrm{~mm}^{3}\right.$ compared to control $(709.2 \pm 36.2)(\mathrm{p}=0.778)$. c Effects of Captopril on hepatocyte apoptosis of colorectal cancer liver metastases following $70 \%$ partial hepatectomy $(\mathrm{PH})$ at day 21 . Hepatocyte apoptosis of Captopril-treated livers $(0.04 \pm 0.03 \%)$ and control livers $(0.3 \pm 0.1)$ were similar at day $21(\mathrm{p}$ $=0.062$ ). $\mathbf{d}$ Effects of Captopril on hepatocyte proliferation in mouse livers with colorectal cancer liver metastases (CRCLM) following 70\% partial hepatectomy (PH) at days 16 and 21. At day 16, hepatocyte proliferation in control CRCLM liver that has undergone $70 \% \mathrm{PH}(1.84 \pm$ $0.36 \%)$ was significantly greater than hepatocyte proliferation in normal livers $(0.6 \pm 0.12 ; \mathrm{p}=$ $0.013)$. Captopril-treated livers at day $16(2.71 \pm 1.16)$ was not significantly different to normal hepatocyte proliferation $(\mathrm{p}=0.162)$. At day 21 , livers with CRCLM that had undergone $70 \% \mathrm{PH}$ had increased hepatocyte proliferation $(4.01 \pm 0.93 \%)$ compared to normal livers $(0.6 \pm 0.12 ; \mathrm{p}=$ 0.041). There was a trend to an increase in hepatocyte proliferation in the Captopril-treated livers $(2.48 \pm 0.65)$ compared to normal hepatocyte proliferation $(\mathrm{p}=0.055)$ at day 21. Captopril did not alter the percentage of hepatocyte proliferation compared to controls at both day $16(\mathrm{p}=$ $0.53)$ and day $21(\mathrm{p}=0.281)$. e-f Immunohistochemical staining of apoptotic control (e) and Captopril-treated (f) hepatocytes at day 21 were stained dark brown (arrow). $\mathbf{g}$ Immunohistochemical staining of proliferating hepatocytes in control tumor on day 16 were stained dark brown (arrow).

Fig 7 mRNA expression levels of angiotensin-converting enzyme (ACE) in colorectal cancer liver metastases and tumor-bearing liver at (a) day 16 and (b) day 21 (mean \pm standard error of the mean, SEM). At day 16, Captopril-treated tumor-bearing liver had higher ACE mRNA levels compared to normal liver $(\mathrm{p}=0.004)$. At day 21 , ACE mRNA levels were increased in the control tumor-bearing liver compared to normal liver. Liver ACE mRNA levels were similar between the Captopril-treated liver and normal liver. At day 16, tumor ACE levels were similar to their liver counterparts in both the controls and Captopril-treated groups. At day 21, ACE mRNA expression was differentially upregulated in control tumors compared to their surrounding liver $(\mathrm{p}=0.004)$. Similarly, tumor ACE mRNA expression levels were upregulated following Captopril treatment compared to their surrounding liver at day $21(\mathrm{p}=0.002)$. At days 16 and 21, Captopril did not alter liver or tumor ACE mRNA levels compared to their respective controls. 